\title{
Influences of Tropical Indian and Pacific Oceans on the Interannual Variations of Precipitation in the Early and Late Rainy Seasons in South China
}

\author{
ChaOXIA YuAn, JunQi LiU, Jing-JiA LuO, AND ZhaOYONG GuAN \\ Key Laboratory of Meteorological Disaster of Ministry of Education, Collaborative Innovation Center on \\ Forecast and Evaluation of Meteorological Disasters, Nanjing University of Information Science and \\ Technology, Nanjing, China
}

(Manuscript received 5 September 2018, in final form 27 February 2019)

\begin{abstract}
Because of the seasonal northward migration of the East Asian summer monsoon, the mean-state atmospheric circulation in South China (SC) is remarkably different between the early (May-June) and late (July-August) rainy seasons. This study presents distinct teleconnections between the SC precipitation in the two periods and the sea surface temperatures (SSTs) in the tropical oceans. In the early rainy season when the major monsoon rain belt is located in SC, the increased local precipitation is related to the tropical Indian Ocean Basin warming. The basin warming induces an anomalous anticyclone in the South China Sea-western North Pacific (SCS-WNP). The related southwesterly anomalies transport more moisture to SC and lead to more moisture convergence and precipitation there. In the late rainy season when the major monsoon rain belt migrates northward to the Yangtze River valley, the precipitation increase in SC can be caused by the dipole SST anomalies in the tropical Pacific with the cold anomalies near the Maritime Continent and warm ones near the date line. The dipole SST anomalies generate an anomalous cyclone in the WNP with its center more northward than that of the anomalous anticyclone in the early rainy season. The related northeasterly anomalies along its northwestern flank reduce the climatological northward transport of moisture flux out of SC, and increase the moisture convergence and precipitation there. The distinct teleconnections between the SC precipitation and the tropical SSTs in the early and late rainy seasons can be well reproduced in the sensitivity experiments by an atmospheric general circulation model.
\end{abstract}

\section{Introduction}

South China (SC) generally refers to the region south of the Yangtze River and east of the Tibetan Plateau (Fig. 1a). It is one of the most economically active centers in China and highly populated. As the wettest region in China, SC experiences strong year-to-year variations in precipitation. Frequent occurrences of flooding often cause tremendous damage to the local economy and ecosystem. For instance, the devastating flooding in the summer of 1994 affected 60 million people, submerged 3.4 million hectares of rice fields, destroyed 800000 houses, and caused direct economic loss around 10 billion U.S. dollars (Xu 1994). Hence, improved understanding of the interannual precipitation variations in SC may help increase the prediction skill of the rainfall variations, which is crucial to the local society.

Corresponding author: Chaoxia Yuan, chaoxia.yuan@nuist.edu.cn
Located in the East Asian monsoon region, the rainy season in SC generally spans from May to August. During this season, over half of the annual total precipitation occurs (Fig. 1b). The onset of the South China Sea monsoon in May often marks the beginning of the East Asian summer monsoon (EASM; Lau and Yang 1997; Wang and Wu 1997; Wang et al. 2004; Zhu et al. 2005; Li and Zhang 2009; Tian and Wang 2010, among others). In May-June (MJ), SC is dominated by the monsoon precipitation (e.g., Chi et al. 2005; Chang et al. 2006) and receives the monthly maximum rainfall in June (Fig. 1b). During July-August (JA), the monsoon-related major rain belt migrates northward to the Yangtze River valley (e.g., Ding and Chan 2005; Wang 2006; Huang et al. 2012), and the precipitation in SC is mainly controlled by the tropical systems such as tropical depressions and cyclones (Ren et al. 2002; Lee et al. 2010). Hence, in accordance with the seasonal northward migration of the summer monsoon circulation and precipitation, the 

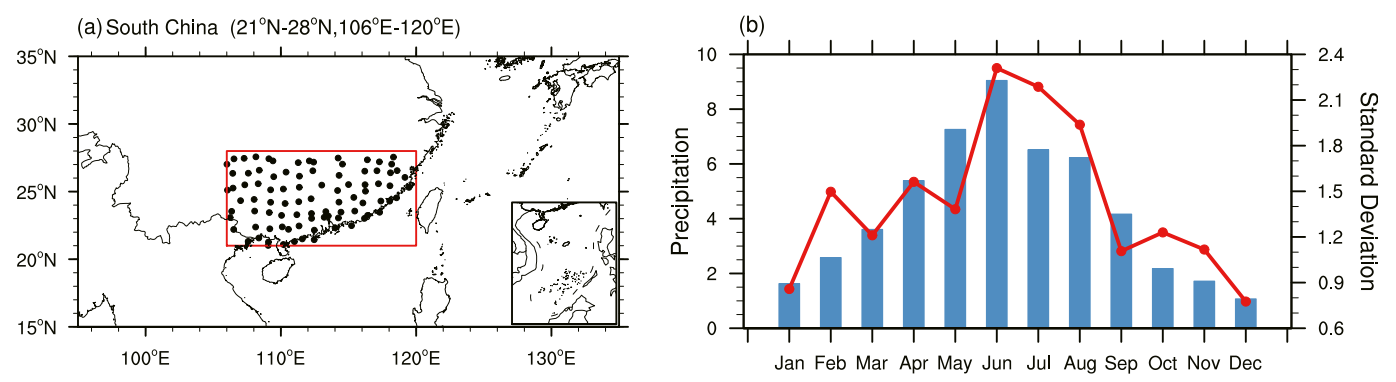

FIG. 1. (a) Distribution of observation stations (dark dots) in SC (red box) and (b) monthly mean (blue bars) and standard deviation (red line) of precipitation $\left(\mathrm{mm} \mathrm{day}^{-1}\right)$ averaged in SC during January 1979-December 2012.

rainy season in SC can be further divided into the early and late periods with the demarcation at the end of June (Yuan et al. 2010; Yuan and Chen 2013).

Underlying mechanisms of the SC summer precipitation variations at the interannual time scale are often linked with those affecting the interannual variations of EASM. Thermal contrast between the Eurasian continent and the surrounding oceans can modify the large-scale atmospheric circulation, the moisture transport from oceans to the continent, and the onset and strength of EASM (e.g., Wu and Qian 2003). ENSO represents the dominant mode of interannual SST variations in the tropical Pacific and exerts significant impacts on the EASM. During the summer of an El Niño decaying year, the western North Pacific (WNP) subtropical high often strengthens and extends westward. This enhances the EASM circulation and results in less precipitation in SC but more in the Yangtze River valley (Chang et al. 2000; Yang and Sun 2005; Bao 2007). The delayed impacts of ENSO on the WNP subtropical high may occur through the local air-sea interaction in the WNP and/or the tropical Indian Ocean (IO) capacitor effect (Wang et al. 2000; Xie et al. 2009; Wang et al. 2013; $\mathrm{Wu}$ et al. 2017a,b). The so-called capacitor effect suggests that El Niño (La Niña) can induce the basin warming (cooling) in the tropical IO that can persist from winter until the subsequent summer, exert influences on the atmospheric circulation via diabatic heating, modify the WNP subtropical high, and thus prolong the ENSO impacts on the EASM. In addition to the impacts on the large-scale monsoon circulation and precipitation, ENSO can also modify the cyclone genesis and tracks in the WNP and influence the frequency of summer precipitation extremes in SC (Zhang et al. 2018). Recently, a new flavor of ENSO was discovered, called ENSO Modoki, warm pool ENSO, or central Pacific ENSO (Ashok et al. 2007; Yu and Kao et al. 2007; Kug et al. 2009). Its related anomalies in SST, convection, atmospheric teleconnection, and climate impacts are remarkably different from those of the canonical ENSO (Weng et al. 2007, 2009). For example, El Niño Modoki induces more summer precipitation in SC, but the canonical El Niño causes less (Karori et al. 2013).

The SST variations in the tropical IO are also an important influence on SC summer precipitation. The IO Basin warming not only impacts the WNP subtropical high, but can also trigger the circumglobal teleconnection in the midlatitudes of the Northern Hemisphere (Yang et al. 2009) and the Pacific-Japan (PJ) pattern in East Asia (Nitta 1987; Tao et al. 2017), influencing the SC summer precipitation. The Indian Ocean dipole (IOD; Saji et al. 1999) is another major mode of SST anomalies in the tropical IO. Tang et al. (2008) showed that a positive IOD leads to more summer precipitation in SC and vice versa for a negative IOD.

In addition to the tropical oceans, the Tibetan Plateau, which is the largest elevated heating source in the Northern Hemisphere, plays an important role in affecting the summer precipitation in SC. It has been shown that more snow over the plateau in late spring and early summer can delay the onset of EASM and thus reduce the SC summer precipitation $(\mathrm{Wu}$ and Qian 2003; Zhang et al. 2004). Wu et al. (2012) showed that the EASM would become much weaker and the summer precipitation in SC would be greatly reduced without the sensible heating of the plateau by using an atmosphere general circulation model.

Most of the existing studies on the SC summer precipitation variations have mainly focused on the seasonal mean anomalies such as May-August or June-August. However, the large-scale atmospheric circulation and the major rain belt location related to the EASM are remarkably different between MJ and JA, in association with the stepwise northward migration of EASM (Wang et al. 2009; Su et al. 2014). During MJ, the inflow of the column-integrated moisture flux through the southern boundary of SC is much larger than the outflow from the northern boundary (Figs. 2a,c), 
(a) MJ

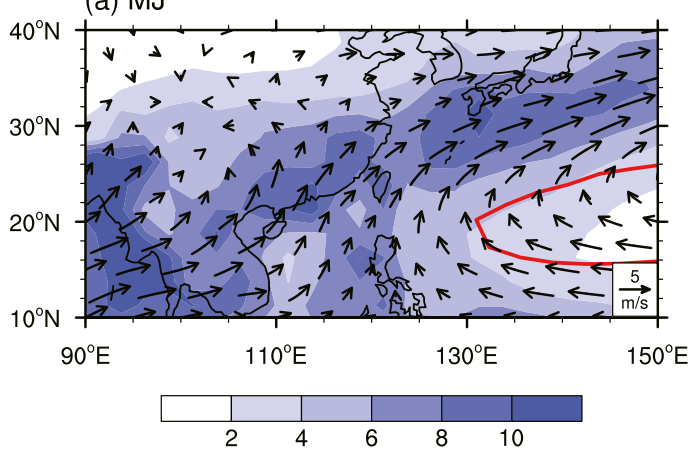

(c) MJ

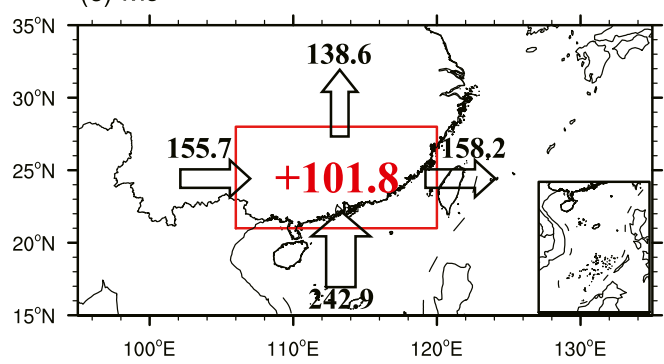

(b) JA

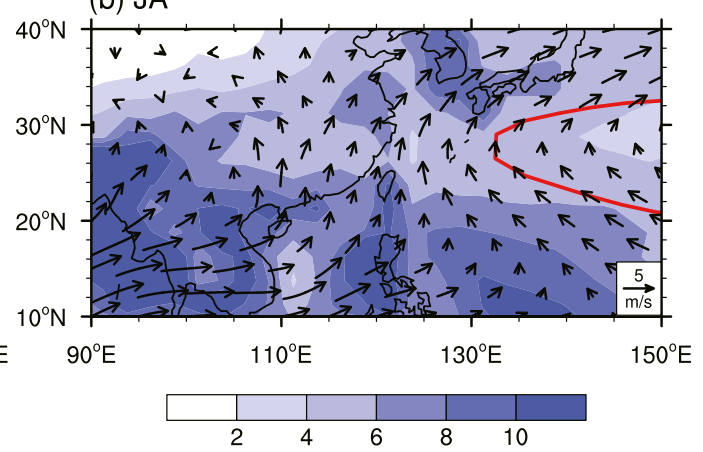

(d) JA

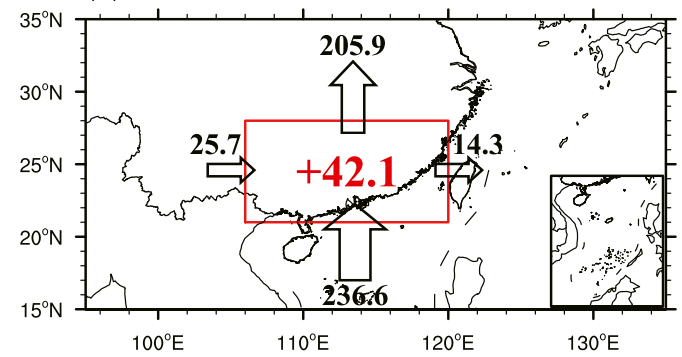

FIG. 2. (a),(c) MJ and (b),(d) JA climatologies of (a),(b) precipitation (shading; mm day $^{-1}$ ) and horizontal winds at $850 \mathrm{hPa}$ (vectors; $\mathrm{m} \mathrm{s}^{-1}$ ) and (c),(d) column-integrated water vapor fluxes crossing four boundaries of SC (black number and open arrow; $10^{6} \mathrm{~kg} \mathrm{~s}^{-1}$ ) and their net convergence in SC (red number; $10^{6} \mathrm{~kg} \mathrm{~s}^{-1}$ ). The red contours in (a) and (b) denote the 5880-gpm contours at $500 \mathrm{hPa}$ that are adopted by National Climate Center in China as the proxy of the edge of the WNP subtropical high.

leading to a large net convergence of the moisture flux there (i.e., $101.8 \times 10^{6} \mathrm{~kg} \mathrm{~s}^{-1}$ ). This is consistent with the formation of the strong monsoon rain belt in SC. In contrast, during JA, accompanying the seasonal northward migration of the EASM system, the lowertropospheric winds over SC become more meridionally oriented, transporting moisture across SC that eventually converges in the lower reaches of Yangtze River (Fig. 2b). Compared to that during MJ, the outflow of the column-integrated moisture flux out of the northern boundary of SC is greatly increased and becomes comparable to the moisture inflow through the southern boundary. Thus, the net convergence of the column-integrated moisture flux in SC is largely reduced (Fig. 2d). We note that the zonal convergence of the moisture flux during both MJ and JA appears to be less important compared to the meridional one. The results suggest that the meridional convergence of the moisture flux plays a dominant role in controlling the rainfall in SC. Increasing the inflow of moisture flux through the southern boundary in $\mathrm{MJ}$ and decreasing the outflow of moisture flux from the northern boundary in JA may both be conducive to enhancement of the summer precipitation in SC. Concerning the distinct differences in the large-scale atmospheric circulation and moisture convergence between MJ and
JA, it is reasonable to examine possible causes of the variations of SC precipitation in the early and late rainy seasons separately for a better understanding of the rainfall variability.

In this study, we investigate the interannual variations of SC precipitation in MJ and JA and examine the possible teleconnections with the tropical SSTs, using the observational and reanalysis data and the numerical simulations. The remaining part of the manuscript is organized as follows. Section 2 briefly introduces the data, the statistical methods, and the atmospheric general circulation model (AGCM) adopted in this study. Section 3 analyzes the interannual variations of $\mathrm{MJ}$ and JA precipitation in SC and their possible teleconnections with the tropical IO and Pacific. Results of the numerical experiments with the AGCM are presented in section 4 . Section 5 gives conclusions and discussion.

\section{Data and methods}

The monthly data used in this study include the station precipitation from the Chinese Meteorological Administration (CMA), NOAA Extended Reconstructed SST (Huang et al. 2015), GPCP v2.3 Combined Precipitation Dataset (Adler et al. 2003), and ERAInterim from the European Centre for Medium-Range 


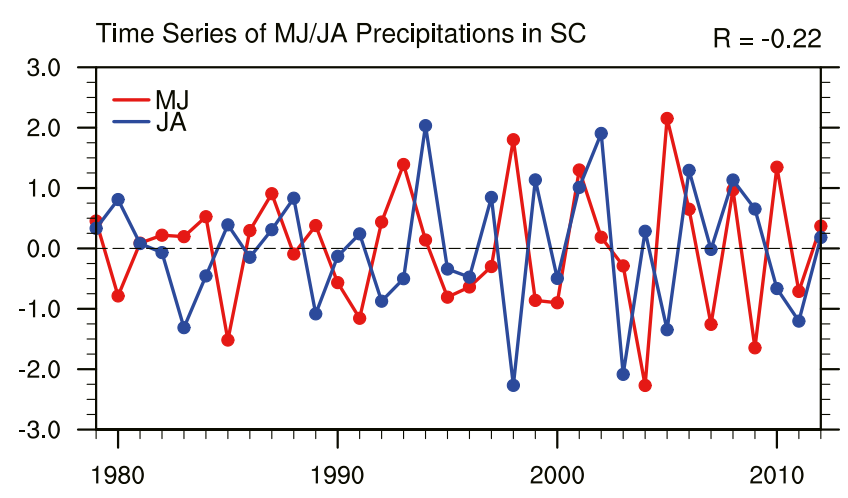

FIG. 3. Time series of normalized region-mean precipitation anomalies in SC in MJ (red) and JA (blue).

Weather Forecasts (ECMWF; Dee et al. 2011) during the period from January 1979 to December 2012. A preliminary quality control is applied to the station precipitation to exclude those stations with missing data during our study period. As a result, a total of 89 stations in $\mathrm{SC}\left(21^{\circ}-28^{\circ} \mathrm{N}, 106^{\circ}-120^{\circ} \mathrm{E}\right)$ are selected (see the dots in Fig. 1a). Since the dominant mode of the MJ (JA) precipitation variations in SC by the empirical orthogonal function (EOF) analysis reflects the spatially consistent anomaly and explains $32 \%(34.5 \%)$ of total variances (figures not shown), the region-mean precipitation anomaly is thus used as the precipitation index in MJ (JA) in SC hereafter. This study focuses on the interannual variations. Hence, linear trends are removed and an 8-yr high-pass Fourier harmonic filter is further applied to extract the interannual components of all data.

The linear correlation and regression analyses are the major methods here. The statistical significance is examined by the two-tailed Student's $t$ test. In addition, the AGCM, version 2.1 (AM2.1), developed by the Geophysical Fluid Dynamics Laboratory (GFDL) Global Atmospheric Model Development Team is adopted for the numerical experiments (Anderson et al. 2004). The model uses a finite-difference formulation and has a $2^{\circ} \times 2.5^{\circ}$ horizontal resolution and 24 vertical levels. It shows a high skill in reproducing the global impacts of the tropical SST anomalies (e.g., Lau et al. 2006; Kosaka et al. 2013).

\section{Interannual variations of SC precipitation in the early and late rainy seasons}

Figure 3 shows the time series of the SC precipitation indices in MJ and JA. It is clear that the two indices have large interannual variations, but share little coherence. The correlation coefficient between them is even negative $(-0.22)$. This suggests that the precipitation anomalies in MJ hardly persist to JA, and averaging the MJ and JA precipitation anomalies will underestimate their variability. Hence, it is necessary to divide the summer rainy season into the early (MJ) and late (JA) periods and to consider their precipitation variations, separately.

In years with above-normal precipitation in $\mathrm{MJ}$, there is an anomalous anticyclone in the lower troposphere centered in the South China Sea (SCS) and WNP region (SCS-WNP) (Fig. 4a). This indicates the intensification and westward shift of the WNP subtropical high compared to its normal situation. The associated southwesterly anomalies along its northwestern edge strengthen the climatological southwesterlies (Fig. 2a), transport more moisture to SC (Fig. 4a), increase the moisture convergence (Fig. 5a), and result in more precipitation in SC (Fig. 4c). The analysis on the moisture flux exhibits that the increased precipitation can be mainly attributed to the enhanced meridional moisture flux entering through the southern boundary of SC. An increase of $\sim 10 \%$ of the climatological moisture flux from the southern boundary in MJ may cause an increase in the precipitation equivalent to one standard deviation of the interannual variability (Figs. $2 \mathrm{c}$ and $5 \mathrm{c}$ ). We note that the zonal moisture flux related to the anomalous anticyclone contributes negatively to the precipitation. This is probably because SC is located in the northwestern portion of the anomalous anticyclone. Hence, the averaged eastward zonal wind anomaly related to the anticyclone crossing the western boundary of SC is smaller than that crossing the eastern boundary. As an example, the averaged zonal wind anomaly at $850 \mathrm{hPa}$ crossing the western boundary is $0.18 \mathrm{~m} \mathrm{~s}^{-1}$, while that crossing the eastern boundary is $0.55 \mathrm{~m} \mathrm{~s}^{-1}$. This may lead to the net zonal moisture flux divergence in SC.

During JA, the major rain belt of EASM shifts northward to the Yangtze River valley in association with the seasonal northward migration of the monsoon 

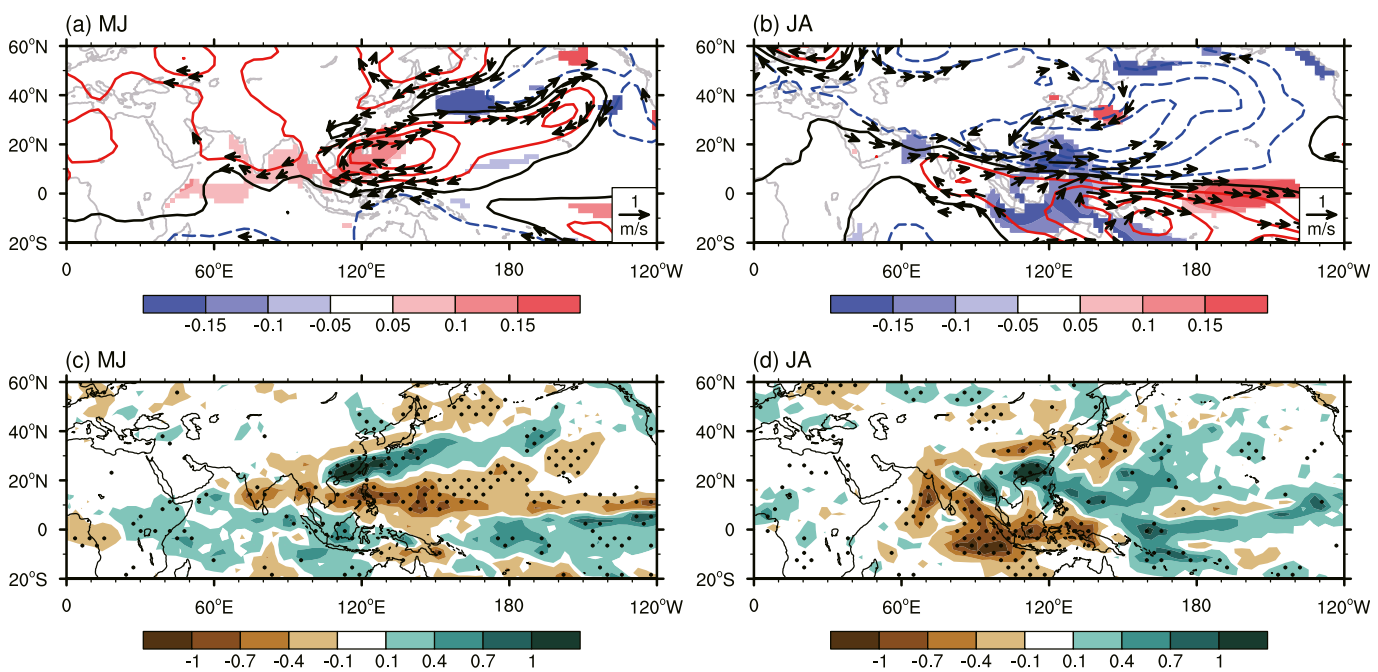

FIG. 4. (a),(c) MJ and (b),(d) JA anomalies of (a),(b) SST (shading; ${ }^{\circ} \mathrm{C}$ ), horizontal wind (vectors; $\mathrm{m} \mathrm{s}^{-1}$ ), and streamfunction (contours; $\mathrm{m}^{2} \mathrm{~s}^{-1}$ ) at $850 \mathrm{hPa}$ and (c),(d) precipitation $\left(\mathrm{mm} \mathrm{day}^{-1}\right.$ ) regressed on MJ and JA precipitation indices in $\mathrm{SC}$ with the indices normalized to have a standard deviation of 1 . Only the anomalies significant at the $90 \%$ confidence level for SST and wind are shown in (a) and (b) and for precipitation (stippled) in (c) and (d). Wind anomalies less than $0.4 \mathrm{~m} \mathrm{~s}^{-1}$ are not shown.

circulation. Correspondingly, abundant moisture is transported through SC, fueling the monsoon rain belt in the north. Distinct from the anomalous features in $\mathrm{MJ}$, the positive precipitation anomalies in SC in JA are closely related to an anomalous cyclone in the WNP with the center being displaced a little northward compared to the aforementioned anomalous anticyclone in MJ (cf. Figs. 4a,b). The associated northeasterly anomalies along the northwestern edge of the anomalous cyclone suppress the climatological northward moisture flux out of the northern boundary of SC (Figs. 2d and 4b), cause more moisture convergence in SC (Fig. 5b), and result in the abovenormal precipitation there (Fig. 4d). A decrease of $\sim 13 \%$ of the climatological northward moisture flux out of the northern boundary may cause a positive precipitation anomaly in SC that is equivalent to one standard deviation of the interannual variability in JA (Fig. 5d).

In summary, associated with the apparent northward migration of the climatological monsoon circulation from MJ to JA, variations in the SC precipitation during the early and late rainy seasons are caused by distinct atmospheric circulation anomalies. During $\mathrm{MJ}$, the positive precipitation anomalies in SC are induced by the anomalous anticyclone around the SCSWNP that increases the inflow of moisture flux through the southern boundary of SC and the moisture convergence there. However, the above-normal JA precipitation in SC is closely linked to the anomalous cyclone in the WNP with its center more northward compared to that of the anomalous anticyclone in MJ. It reduces the outflow of moisture flux from the northern boundary of SC and consequently increases the local moisture convergence and precipitation. The different atmospheric circulation anomalies between MJ and JA indicate the distinct mechanisms that underpin the precipitation variations in the early and late rainy seasons in SC. This may partly explain the negative, albeit not significant, correlation between the MJ and JA precipitation indices (recall Fig. 3).

\section{Remote influences of the tropical Indian and Pacific Oceans}

In the section, we aim to investigate the possible drivers of the anomalous anticyclone in $\mathrm{MJ}$ and cyclone in JA that tend to increase the precipitation in SC. It is found that the increased MJ precipitation is closely related to the IO Basin warming (Fig. 4a); the linear correlation coefficient between the IO Basin warming index (i.e., SST anomalies averaged over $10^{\circ} \mathrm{S}-20^{\circ} \mathrm{N}$, $50^{\circ}-100^{\circ} \mathrm{E}$ ) and the $\mathrm{MJ}$ precipitation indices is 0.33 , significant at the $90 \%$ confidence level (Fig. 6a). This is consistent with previous studies showing that the diabatic heating induced by the IO Basin warming in late spring and summer can excite the warm atmospheric Kelvin wave along the equator that propagates eastward to the tropical western Pacific, causing surface convergence on the equator but divergence in the offequatorial regions, and thus results in the anomalous 
(a) $\mathrm{MJ}$

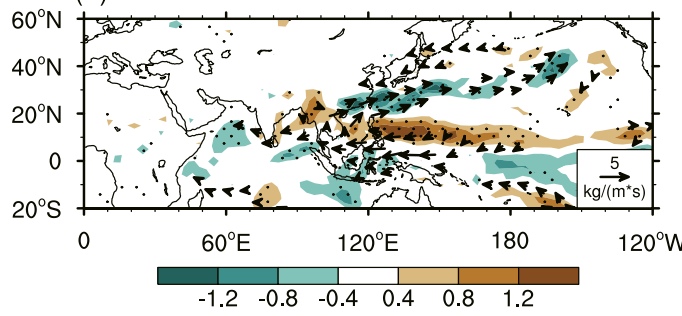

(c) $\mathrm{MJ}$

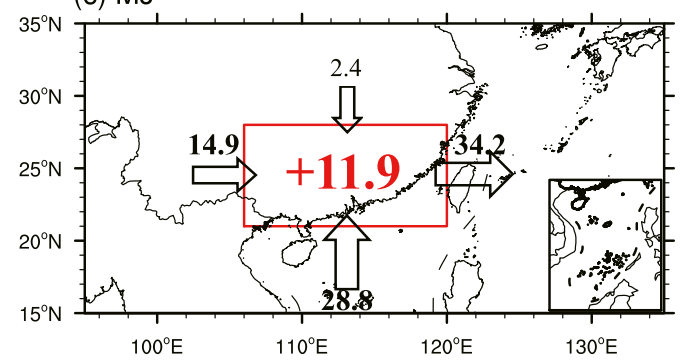

(b) JA

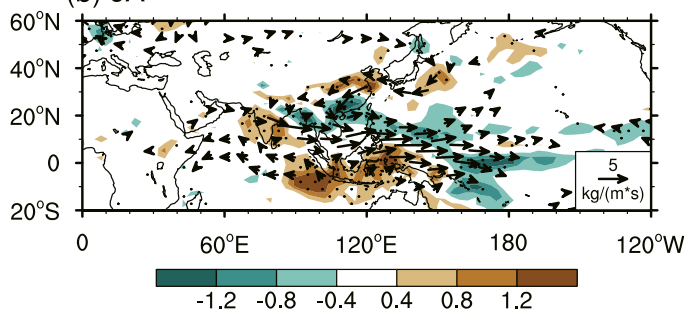

(d) JA

FIG. 5. (a),(c) MJ and (b),(d) JA anomalies of (a),(b) column-integrated moisture flux (vectors; $10^{-6} \mathrm{~kg} \mathrm{~m}^{-1} \mathrm{~s}^{-1}$ ) and its divergence (shading; $10^{-6} \mathrm{~kg} \mathrm{~m}^{-1} \mathrm{~s}^{-2}$; negative values denoting convergence) and (c),(d) its amount (dark numbers; $10^{6} \mathrm{~kg} \mathrm{~s}^{-1}$ ) crossing four boundaries of SC and the net convergence in SC (red numbers; $10^{6} \mathrm{~kg} \mathrm{~s}^{-1}$ ). The anomalies in (a) and (c) and in (b) and (d) are regressed respectively on MJ and JA precipitation indices in SC with the indices normalized to have a standard deviation of 1 . Only anomalies significant at the $90 \%$ confidence level for the column-integrated moisture flux are shown in (a) and (b); for the moisture flux convergence they are stippled in (a) and (b), and for the moisture flux amount crossing four boundaries of SC they are boldface in (c) and (d).

anticyclone in the SCS-WNP (Xie et al. 2009, 2016; Chowdary et al. 2011). The anomalous anticyclone strengthens the climatological southwesterlies crossing the southern boundary of SC and brings the abovenormal precipitation to SC. We note that, in addition to the IO Basin warming, significant positive SST anomalies also appear in SCS and the ocean east of the Philippines during a wet early rainy season in SC (Fig. 4a). However, these warm SST anomalies sit right under the anomalous anticyclone and are associated with less-than-normal precipitation (Fig. 4c). Since the active warm SST anomalies in the tropical region usually enhance the precipitation and induce anomalous cyclonic circulation in the lower troposphere, we speculate that the warm SST anomalies may be caused by an increased shortwave radiation due to less cloud in the anomalous anticyclone area. Therefore, they may happen as a response to the high pressure anomaly rather than the other way around (Klein et al. 1999; Wu et al. 2014).

Interestingly, the anomalous cyclone in the WNP during JA that introduces the above-normal precipitation in SC appears to be related to the dipole SST anomalies in the tropical Pacific with the cold anomalies around the Maritime Continent and warm ones near the date line (Fig. 4b). The dipole SST anomalies are analogous to those related to a developing El Niño
Modoki in summer (Weng et al. 2007). In fact, the 2 years with the highest JA precipitation in SC occurred during the typical El Niño Modoki years in 1994 and 2002 (Fig. 3). The dipole SST anomalies can reduce the precipitation in the cold pole, enhance the precipitation in the warm pole, and induce the anomalous cyclonic circulation between them in the off-equatorial region (Figs. 4b and 4d). This is actually the typical atmospheric response to the anomalous dipole heating on the equator, as illustrated by the classical shallowwater model of Matsuno (1966) and Gill (1980) with the cooling in the west and the heating in the east (Fig. 7). If we define the dipole SST index in the tropical Pacific as the difference in the region-mean SST anomalies between the western $\left(10^{\circ} \mathrm{S}-10^{\circ} \mathrm{N}, 90^{\circ}-140^{\circ} \mathrm{E}\right)$ and eastern $\left(10^{\circ} \mathrm{S}-10^{\circ} \mathrm{N}, 170^{\circ} \mathrm{E}-140^{\circ} \mathrm{W}\right)$ poles, the linear correlation coefficient between the dipole SST and the JA precipitation indices reaches 0.51 , significant at the 99\% confidence level (Fig. 6b).

\section{AGCM simulations}

The observed teleconnections between the tropical IO and Pacific SSTs and the SC precipitation in the early and late rainy seasons are further verified by conducting a control (CTRL) and two sensitivity experiments (TI and TP) in AM2.1. In all the three experiments, the $\mathrm{CO}_{2}$ 

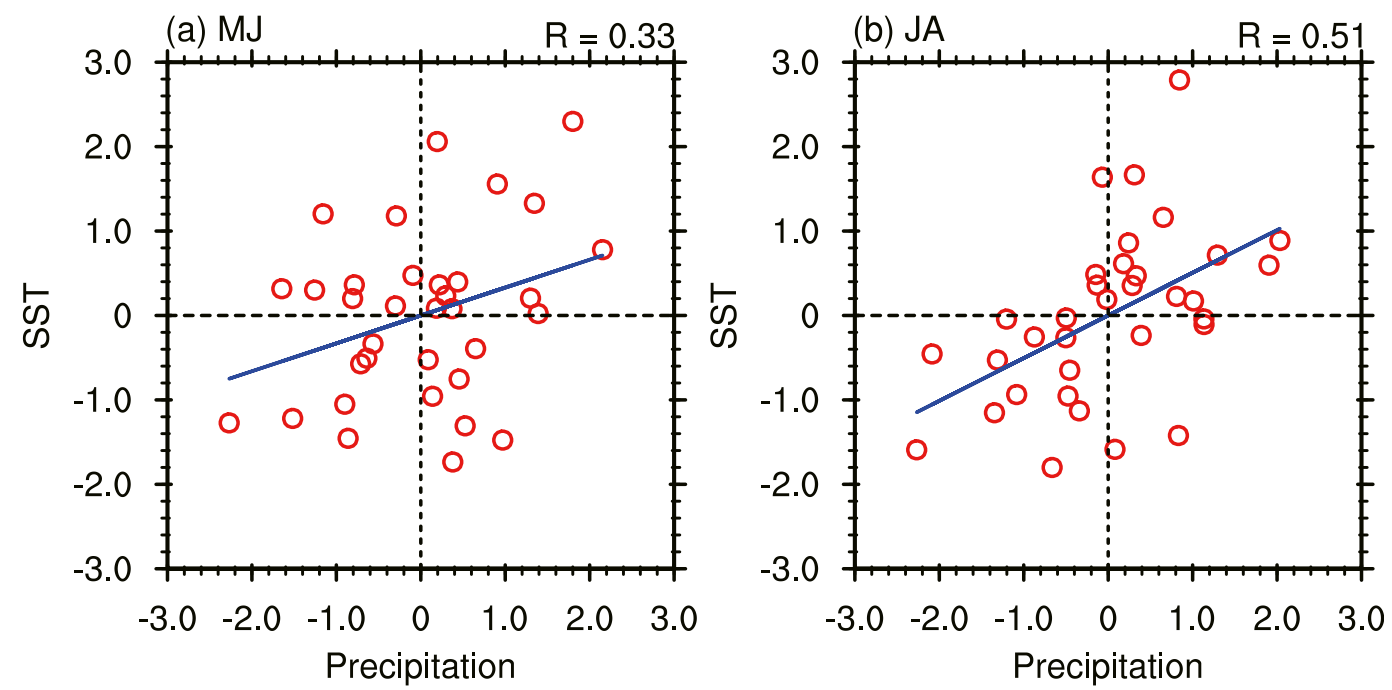

FIG. 6. Scatterplots of (a) the IO Basin warming indices and the MJ precipitation anomalies in SC and (b) the dipole SST indices in the tropical Pacific and the JA precipitation anomalies in SC.

concentration and other anthropogenic forcing are fixed at the preindustrial levels in the year 1860. The CTRL run is forced by the monthly SST climatology as the lower boundary forcing and integrated for 40 years. The outputs of the last 30 years are used to calculate the model climatology. The TI run is initialized by the atmospheric condition on 1 May in each year of the last 20 years of CTRL, forced by the monthly SST climatology plus $0.5^{\circ} \mathrm{C}$ in the tropical IO $\left(10^{\circ} \mathrm{S}-20^{\circ} \mathrm{N}, 50^{\circ}-100^{\circ} \mathrm{E}\right)$ in $\mathrm{MJ}$, and integrated for 2 months to verify the observed impacts of the MJ IO Basin warming on the MJ precipitation in SC (Fig. 8a). Similarly, the TP run is initialized by the atmospheric condition on 1 July in each year of the last 20 years of CTRL, forced by the monthly SST climatology plus $0.5^{\circ} \mathrm{C}$ in the tropical central Pacific $\left(10^{\circ} \mathrm{S}-10^{\circ} \mathrm{N}, 170^{\circ} \mathrm{E}-140^{\circ} \mathrm{W}\right)$ and $-0.5^{\circ} \mathrm{C}$ near the Maritime Continent $\left(10^{\circ} \mathrm{S}-10^{\circ} \mathrm{N}\right.$, $90^{\circ}-140^{\circ} \mathrm{E}$ ) in $\mathrm{JA}$, and integrated for 2 months to verify the observed impacts of the JA dipole SST anomalies in the tropical Pacific on the JA precipitation in SC (Fig. 8b). Both of the TI and TP experiments have 20 ensembles. Deviation of the ensemble mean from the model climatology is regarded as the simulated atmospheric response to the anomalous SST forcing. The statistical significance of the response is examined by the two-tailed $t$ test. We note that the up-to-date models have limited skills in simulating the climatology and interannual variations of the East Asian summer climate (e.g., Seo et al. 2013; Song and Zhou 2014). Hence the SST anomalies applied in the sensitivity experiments, especially in the TI, are higher than the observed to attain a larger signal-to-noise ratio and to qualitatively simulate the impacts of tropical SSTs on the SC summer precipitation.
Figures $8 \mathrm{a}$ and $8 \mathrm{c}$ show the modeled atmospheric circulation and precipitation responses in the TI experiment to the forcing of IO Basin warming in MJ. As expected, the model reproduces well the increased precipitation in the tropical IO, the anomalous anticyclone and reduced precipitation over the SCS-WNP, and the increased precipitation from SC extending northeastward to the south of Japan as in the observations. This supports our hypothesis that the IO Basin warming in $\mathrm{MJ}$ can increase the precipitation in SC by generating the anomalous anticyclone over the SCS-WNP that transports more moisture to SC and leads to more precipitation there. It is worth noting that although we have had to scale the SST forcing up by roughly a factor of 4 in the model compared to the observed to attain a larger signal-to-noise ratio (Figs. $4 \mathrm{a}$ and $8 \mathrm{a}$ ), the simulated precipitation responses in the tropical IO are about 4 times larger than the observed, indicating that there is some quantitative consistency between the precipitation anomalies that the model produces and those that are found in observations.

We note that the simulated positive precipitation anomaly in SC is not statistically significant in the TI experiment. This is probably due to the model deficiency in simulating the proper precipitation anomaly in the EASM region, especially over the land. Song and Zhou (2014) showed that provided the observed historical global SST anomalies, most AGCMs from both phases 3 and 5 of the Coupled Model Intercomparison Project (CMIP) failed to simulate the observed summer precipitation anomalies in East Asia. In addition, the IO SST anomalies explain around $\sim 10 \%$ of the observed total interannual variances of $\mathrm{SC}$ precipitation in 


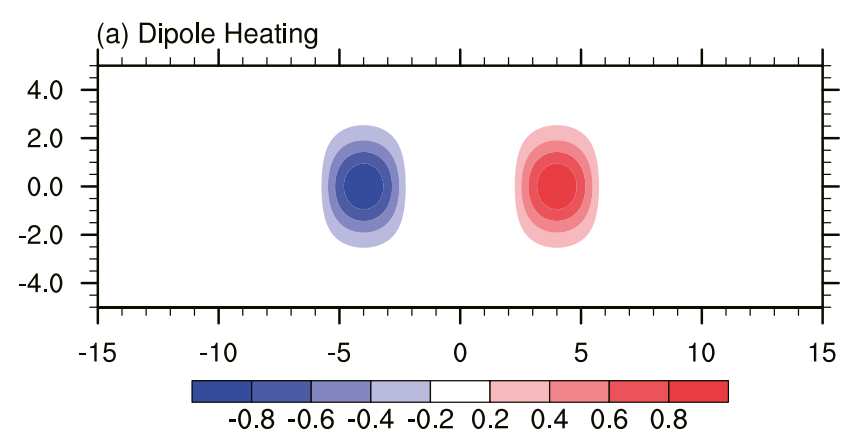

(b) StreamF \& R wind
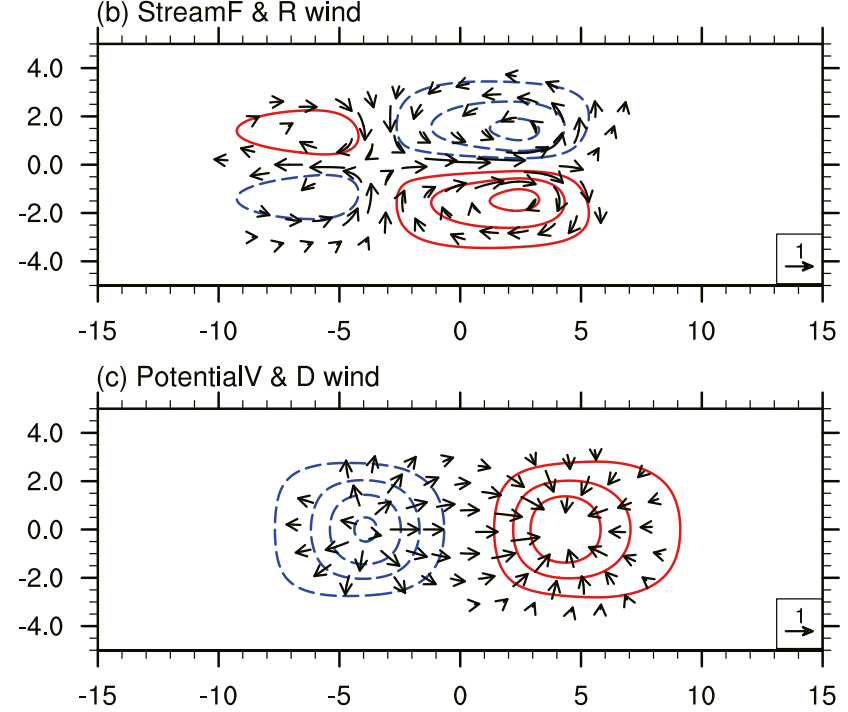

FIG. 7. (a) A pair of dipole diabatic heating along the equator and the associated responses of (b) the streamfunction and rotational wind and (c) the velocity potential and divergent wind in the lower troposphere, as simulated by the Matsuno-Gill model.

MJ on which the internal variability may play a role. Hence, it could be hard to simulate the SST impacts in the model perfectly. We also note that the cyclonic circulation anomalies straddling the western equatorial IO as the Matsuno-Gill response are predominant in the TI experiment but not in the observation. This is probably partly because the SST forcing in the TI experiment is much higher than the observed (cf. Figs. 4a and $8 \mathrm{a}$ ) in order to get the stronger warm Kelvin wave propagating into the tropical Pacific before it dissipates. Also, the interbasin coupling between the IO and the SCS-WNP that may change the atmospheric circulation in IO is not fully permitted in the AGCM simulations (e.g., Xie et al. 2016).

In the TP experiment, the dipole SST forcing in JA induces the dipole precipitation anomalies in the tropical Pacific and the anomalous cyclone between them in the WNP (Figs. 8b,d). As in the observations (Figs. 4b,d), the anomalous northeasterlies along the northwestern edge of the anomalous cyclone weaken the climatological northward transport of moisture flux from SC to the Yangtze River valley, leading to more precipitation in SC but less in the Yangtze River valley (Figs. 8b,d). It is worth mentioning that an anomalous anticyclone and reduced precipitation can also be discerned northeast of the anomalous cyclone around Japan in the TP run. This is reminiscent of the PJ pattern, the dominant tropical-extratropical atmospheric teleconnection in the boreal summer in the WNP (Nitta 1987). Srinivas et al. (2018) discussed the impacts of the PJ pattern on the Indian summer rainfall; the anomalous westerlies along the southern flank of the anomalous cyclone in the WNP related to the PJ pattern extend westward to the Indian subcontinent, reducing the precipitation in the southern and northern India but enhancing that in the central India. The summer precipitation anomalies in India related to the PJ pattern can be well seen in both the observations and model simulation (Figs. 4b,d and 8b,d). This indicates that the dipole SST anomalies in the tropical 

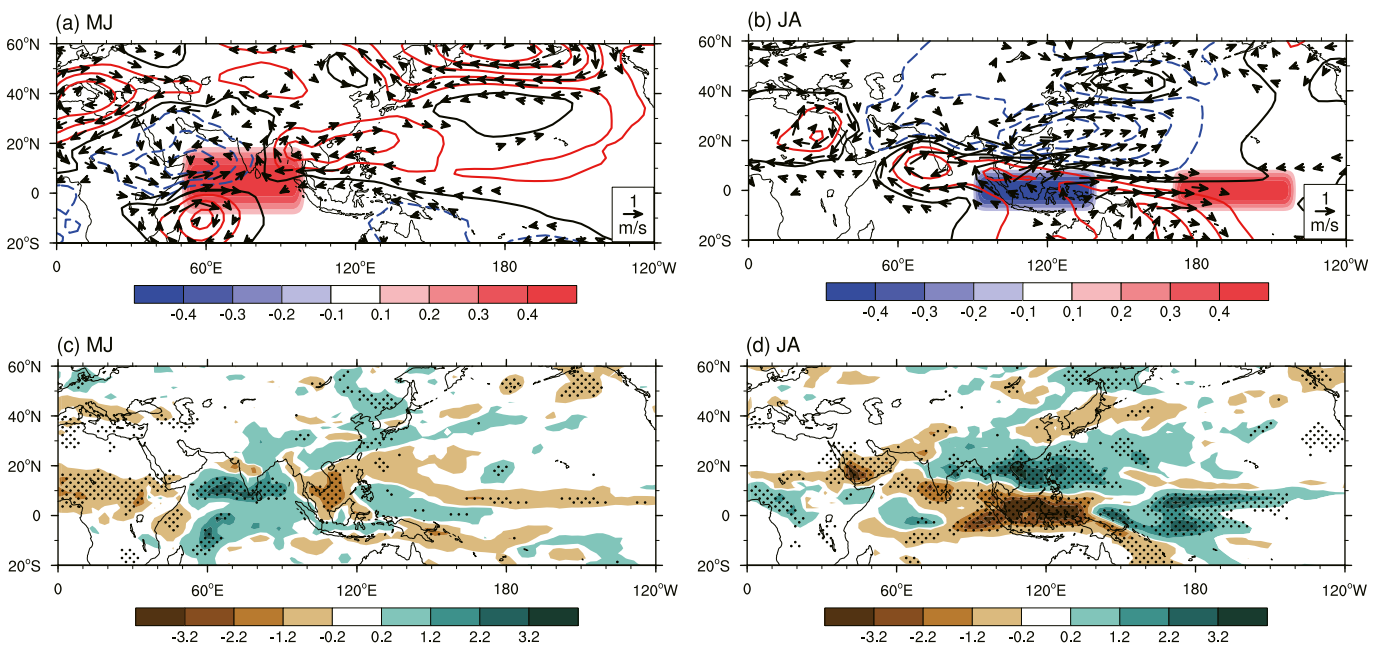

FIG. 8. (a),(c) MJ and (b),(d) JA SST forcing and the corresponding ensemble-mean responses of (a),(b) the horizontal wind (vectors; $\mathrm{m} \mathrm{s}^{-1}$ ) and streamfunction (contours; $\mathrm{m}^{2} \mathrm{~s}^{-1}$ ) at $850 \mathrm{hPa}$ and (c),(d) precipitation (shading; $\mathrm{mm} \mathrm{day}^{-1}$ ) in GFDL AM2.1. The number of ensemble members is 20. Only anomalies significant at the $90 \%$ confidence level for wind are shown in (a) and (b) and for precipitation they are stippled in (c) and (d). The wind anomalies less than $0.4 \mathrm{~m} \mathrm{~s}^{-1}$ are not shown.

Pacific analogous to the developing ENSO Modoki may be able to excite the PJ pattern and influence not only the summer climate in East Asia (Kosaka et al. 2013) but also the Indian summer rainfall (Srinivas et al. 2018).

In summary, although the model simulation has some deficiencies, the TI and TP experiments basically confirm the observed remote impacts of the SST anomalies in the tropical IO and Pacific on the SC precipitation in the early and late rainy seasons, respectively.

\section{Conclusions and discussion}

The interannual variations of precipitation in SC during the early (MJ) and late (JA) rainy seasons have been investigated. Results show that the precipitation variations in the two periods have little coherence; the linear correlation coefficient between them is -0.22 , which is not statistically significant. The above-normal MJ precipitation is closely related to an anomalous anticyclone in the SCS-WNP, whereas the abovenormal JA precipitation is caused by an anomalous cyclone in the WNP with its center being displaced a little northward compared to the center of the anomalous anticyclone in MJ. The differences in the atmospheric circulation anomalies between MJ and JA are due to the seasonal evolution of the EASM system. In MJ, the monsoon rain belt is located in SC. Correspondingly, as illustrated schematically in Fig. 9a, the anomalous anticyclone in the SCS-WNP can increase the precipitation in SC by intensifying the climatological southwesterlies and increasing moisture convergence in SC. In JA, the monsoon major rain belt moves northward to the Yangtze River valley. The monsoonal airflows carry abundant moisture farther northward, passing through SC and converging in the north. Consistently, during JA, the northeasterlies along the northwestern part of the anomalous cyclone in the WNP suppress the northward transport of moisture out of the northern boundary of SC, increase the local moisture convergence, and lead to the more-than-normal precipitation in SC (Fig. 9b).

The anomalous anticyclone in the SCS-WNP during MJ can be driven by the IO Basin warming, whereas the anomalous cyclone in the WNP in JA can be caused by the zonal dipole SST anomalies in the tropical Pacific. The sensitivity experiments with GFDL AM2.1 well reproduce the distinct remote influences of the tropical SSTs on the SC precipitation during MJ and JA. Forced by the IO Basin warming in MJ, the model successfully reproduces the observed anomalous anticyclone in the SCS-WNP and the positive precipitation anomaly in SC. Forced by the zonal dipole SST anomalies in the tropical Pacific with the cold pole being specified around the Maritime Continent and the warm pole near the date line in JA, the model well reproduces the observed anomalous cyclone in the WNP and the above-normal precipitation in SC. This confirms the important and distinct roles of the tropical IO and the Pacific SSTs in causing the interannual variations of the SC precipitation during MJ and JA, respectively. 
(a) $\mathrm{MJ}$

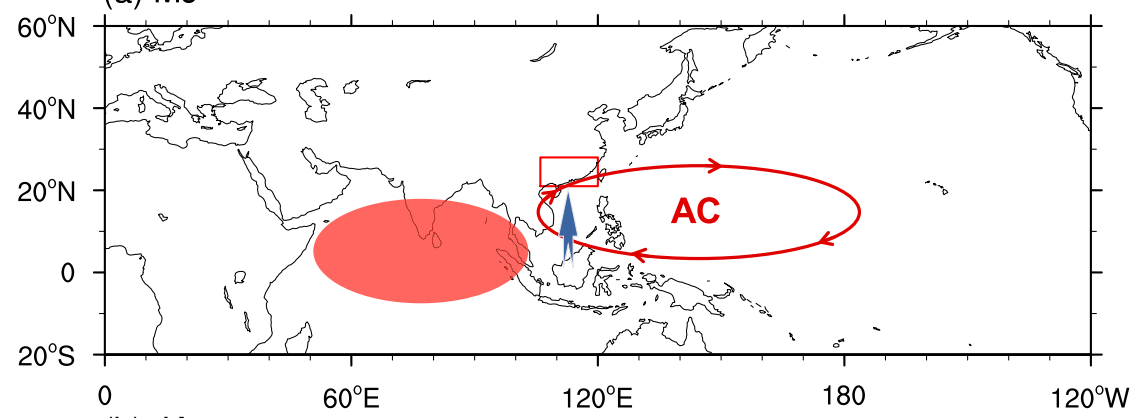

(b) JA

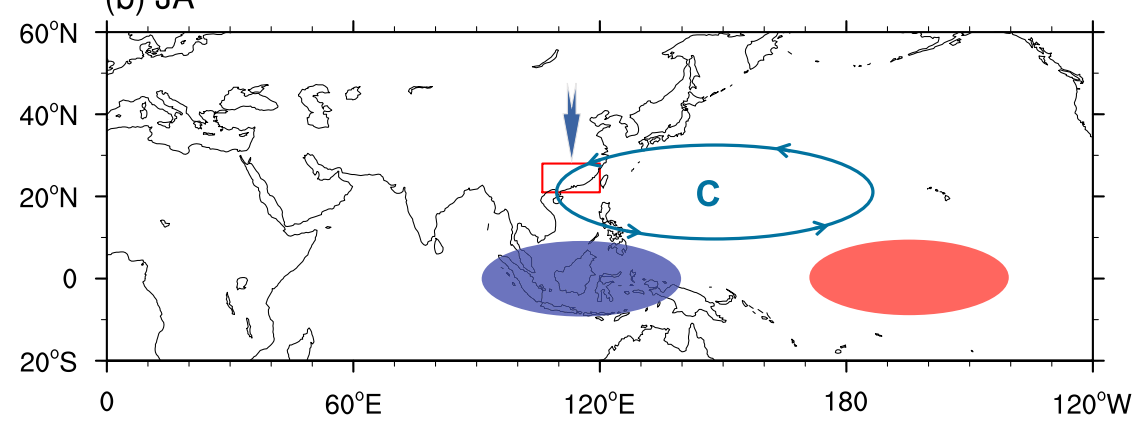

FIG. 9. Schematic diagram of mechanisms describing influences of (a) the IO Basin warming on the atmospheric circulation during the early rainy season in SC and (b) the zonal dipole SST in the tropical Pacific on atmospheric circulation during the late rainy season in SC. The red (blue) shading denotes positive (negative) SST anomalies. The red (blue) contour denotes the anomalous anticyclone (cyclone) in the WNP. Blue arrows denote the direction of significant anomalies in the column-integrated water vapor flux into SC.

Since the tropical SSTs have much higher predictability than the summer precipitation in East Asia (Luo et al. 2016), our results may be helpful for increasing the prediction skills of the summer precipitation in SC by establishing the significant relationship with the tropical SSTs.

In over one-third of cases, the IO Basin warming persists from MJ to JA (Guo et al. 2018). However, its impacts on the SC precipitation differ between $\mathrm{MJ}$ and JA. The IO Basin warming during JA can also induce an anomalous anticyclone in the WNP, but the anomalous anticyclone is located more northward than that in MJ (figure not shown). Consequently, the moisture transport out of the northern boundary of SC is higher than that into SC through the southern boundary, leading to less precipitation in SC, although this is not statistically significant. Similarly, we find that the dipole SST anomalies in the tropical Pacific in MJ have little impact on the SC precipitation. This may be partly due to the different mean states in MJ and JA. Moreover, the dipole SST anomalies have smaller amplitude in MJ than in JA, analogous to the case of ENSO, which grows in summer (Larkin et al. 2002; Xie et al. 2016). As a result, they generate an anomalous cyclone response in $\mathrm{MJ}$ much more southeastward than that in JA and thus exert little impact on SC (figure not shown). Because of the distinct mechanisms in the early and late rainy seasons, a simple average of the MJ and JA precipitation in SC may greatly mask out their relation with the tropical IO and Pacific. Indeed, a significant correlation coefficient is not found between the May-August precipitation in SC and the tropical SSTs; the correlation coefficient of the May-August SC precipitation with IO Basin warming indices is -0.08 and that with the zonal dipole SST indices in the tropical Pacific is 0.22 (Fig. 10). This is in stark contrast to the relation during MJ and JA (see Fig. 4). Hence, it is necessary to divide the summer (May-August) into the early and late periods and investigate their precipitation variations separately in SC.

The precipitation in SC has exhibited a linear positive trend. According to China's National Assessment Report on Climate Change, the annual precipitation in SC has increased around $60-130 \mathrm{~mm}$ during the last 50 years (Ding et al. 2007). The frequency of precipitation extremes has also increased (Zhai et al. 2005; You et al. 2011; Zhou et al. 2014). Since the precipitation extremes are closely related to the catastrophic hazards, we have also examined their relation with the tropical SSTs. The precipitation extremes here are represented 
(a)

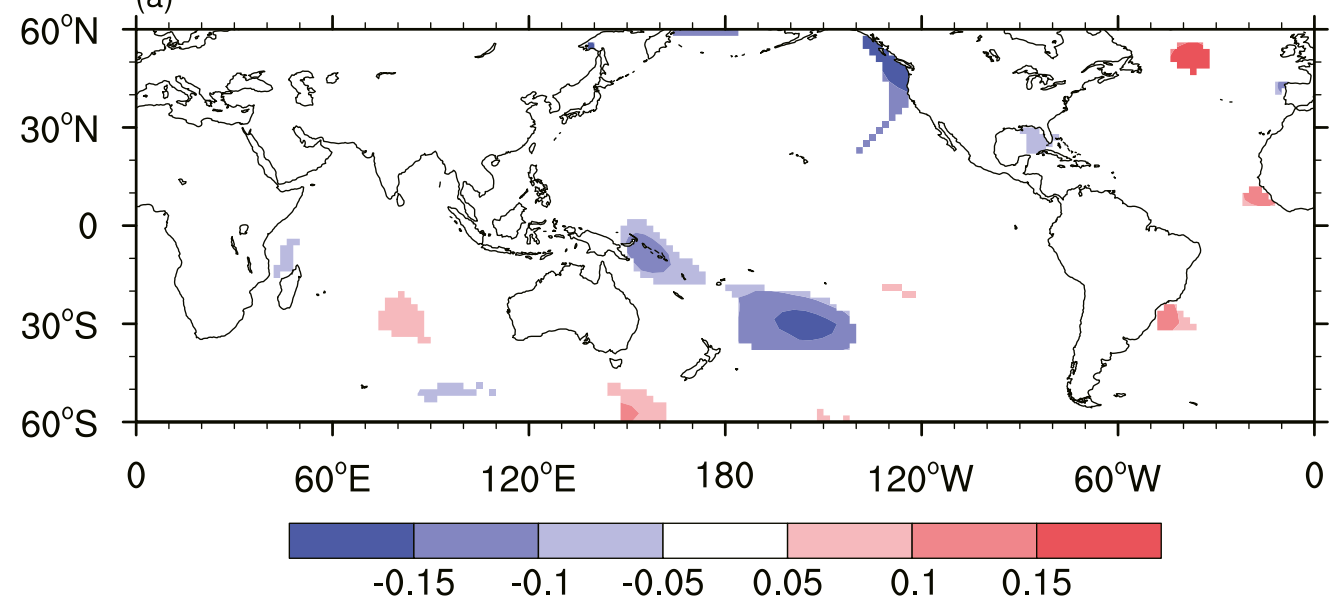

(b)

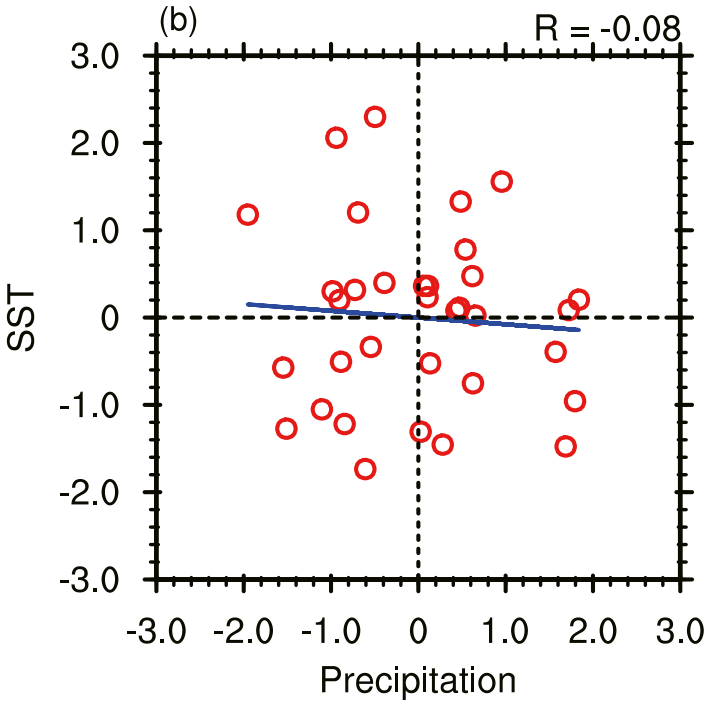

(c)

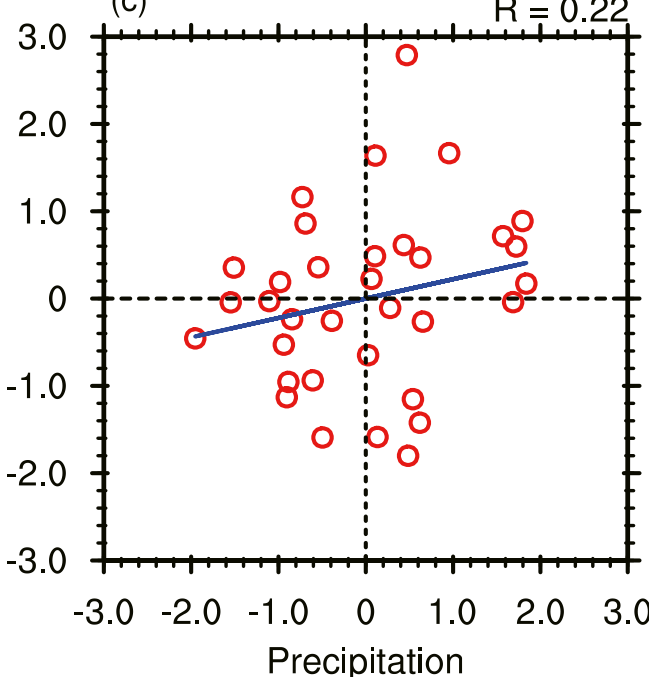

FIG. 10. (a) SST anomalies (shading; ${ }^{\circ} \mathrm{C}$ ) regressed on May-August precipitation anomalies in SC with the precipitation anomalies normalized to have a standard deviation of 1 . Scatterplots of May-August precipitation anomalies in SC with (b) IO Basin warming indices and (c) the zonal dipole index of SST anomalies in the tropical Pacific. Correlation coefficients $R$ are shown in the upper right of (b) and (c).

by R95p (i.e., the accumulation of daily precipitation), which exceeds the 95th percentile of the all wet days in our study period (Zhang et al. 2011). Similar results are attained (Fig. 11). That is, the increase in the
MJ precipitation extremes in SC is closely related to the anomalous anticyclone in the SCS-WNP and the IO Basin warming. Also, the increase in the JA precipitation extremes is caused by the anomalous
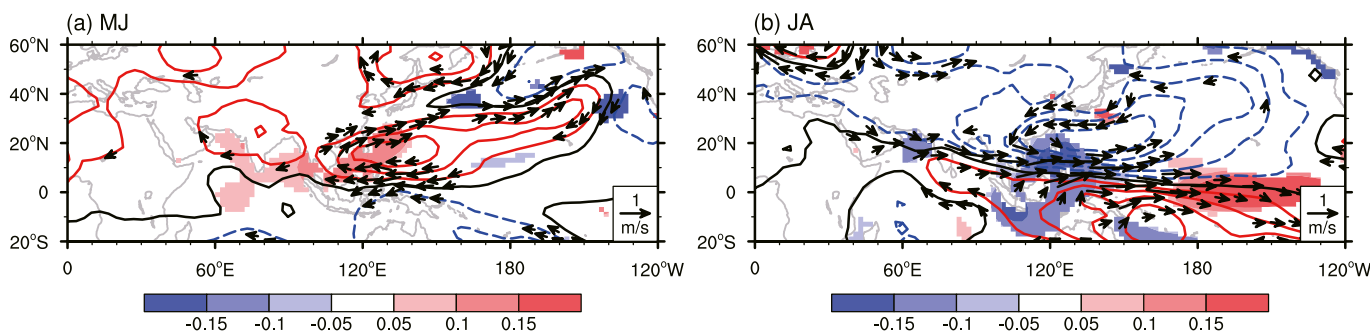

FIG. 11. As in Figs. 4a and 4b, but for the anomalies regressed on (a) MJ and (b) JA precipitation extreme indices in $\mathrm{SC}$ with the precipitation extremes indices normalized to have a standard deviation of 1 . 
cyclone in the WNP and the zonal dipole SST anomalies in the tropical Pacific. Using different indices of precipitation extremes will not change the major conclusions here. Therefore, the SST anomalies in the tropical IO and Pacific influence not only the seasonalmean precipitation but also the frequency of precipitation extremes in SC.

In addition to the impacts of the tropical SSTs as shown in this study, the summer precipitation in SC can also be influenced by the intrusion of cold air from high latitudes and the synoptic systems propagating from the Tibetan Plateau (Yang et al. 2017; Kong et al. 2017). Enhancement of the summer northern East Asian low (Lin and Wang 2016) and the extent of the spring sea ice in the Okhotsk and Bering Seas (Zhao et al. 2004) also play an important role on the summer precipitation variations. It would be interesting to examine whether the impacts of these factors on the SC precipitation are also different between the early and late rainy seasons. However, this is beyond the scope of the present study, and future investigation is warranted in order to improve our understanding of the SC precipitation variations.

Acknowledgments. The authors are very thankful to the two anonymous reviewers for their constructive comments that helped to improve the research greatly. GPCP precipitation data were provided by the NOAA/OAR/ ESRL PSD, Boulder, Colorado, USA, from their Web site at https://www.esrl.noaa.gov/psd/. All figures here were drawn by NCL. The research is financially supported by the National Key R\&D Program of China Grants 2016YFA0600702 and 2016YFA0600402, the National Nature Science Foundation of China under Grant 41875099 , and the funding of Jiangsu innovation and entrepreneurship team.

\section{REFERENCES}

Adler, R., and Coauthors, 2003: The version-2 Global Precipitation Climatology Project (GPCP) monthly precipitation analysis (1979-present). J. Hydrometeor., 4, 1147-1167, https://doi.org/ 10.1175/1525-7541(2003)004<1147:TVGPCP $>2.0$.CO;2.

Anderson, J. L., and Coauthors, 2004: The new GFDL global atmosphere and land model AM2-LM2: Evaluation with prescribed SST simulations. J. Climate, 17, 4641-4673, https:// doi.org/10.1175/jcli-3223.1.

Ashok, K., S. K. Behera, S. A. Rao, H. Weng, and T. Yamagata, 2007: El Niño Modoki and its possible teleconnection. J. Geophys. Res., 112, C11007, https://doi.org/10.1029/2006JC003798.

Bao, M., 2007: The statistical analysis of the persistent heavy rain in the last 50 years over China and their backgrounds on the large scale circulation (in Chinese). Chin. J. Atmos. Sci., 31, 779-792.

Chang, C.-P., Y. Zhang, and T. Li, 2000: Interannual and interdecadal variations of the East Asian summer monsoon and tropical Pacific SSTs. Part I: Roles of the subtropical ridge.
J. Climate, 13, 4310-4325, https://doi.org/10.1175/15200442(2000)013<4310:IAIVOT>2.0.CO;2.

Chang, Y., J. He, Y. Liu, and P. Liang, 2006: Features of moisture transport of in pre-summer flood season of drought and flood years over South China (in Chinese). Plateau Meteor., 25, 1064-1070.

Chi, Y., J. He, and Z. Wu, 2005: Features analysis of the different precipitation periods in the pre-rainy season in South China (in Chinese). J. Nanjing Inst. Meteor., 28, 163-171.

Chowdary, J. S., S.-P. Xie, J.-J. Luo, J. Hafner, S. Behera, Y. Masumoto, and T. Yamagata, 2011: Predictability of Northwest Pacific climate during summer and the role of the tropical Indian Ocean. Climate Dyn., 36, 607-621, https:// doi.org/10.1007/s00382-009-0686-5.

Dee, D. P., and Coauthors, 2011: The ERA-Interim reanalysis: Configuration and performance of the data assimilation system. Quart. J. Roy. Meteor. Soc., 137, 553-597, https://doi.org/ 10.1002/qj.828.

Ding, Y., and J. C. L. Chan, 2005: The East Asian summer monsoon: An overview. Meteor. Atmos. Phys., 89, 117-142, https:// doi.org/10.1007/s00703-005-0125-z.

_- and Coauthors, 2007: China's National Assessment Report on Climate Change (I): Climate change in China and the future trend. Adv. Climate Change Res., 3 (Suppl.), 1-5, https:// www.researchgate.net/publication/242281068_China's_National_ Assessment_Report_on_Climate_Change_I_Climate_change_ in_China_and_the_future_trend.

Gill, A. E., 1980: Some simple solutions for heat-induced tropical circulation. Quart. J. Roy. Meteor. Soc., 106, 447-462, https:// doi.org/10.1002/qj.49710644905.

Guo, F., Q. Liu, J. Yang, and L. Fan, 2018: Three types of Indian Ocean basin modes. Climate Dyn., 51, 4357-4370, https:// doi.org/10.1007/s00382-017-3676-z.

Huang, B., and Coauthors, 2015: Extended Reconstructed Sea Surface Temperature version 4 (ERSST.v4): Part I. Upgrades and intercomparisons. J. Climate, 28, 911-930, https://doi.org/ 10.1175/JCLI-D-14-00006.1.

Huang, R., J. Chen, L. Wang, and Z. Lin, 2012: Characteristics, processes, and causes of the spatio-temporal variabilities of the East Asian monsoon system. Adv. Atmos. Sci., 29, 910942, https://doi.org/10.1007/s00376-012-2015-x.

Karori, M. A., J. Li, and F.-F. Jin, 2013: The asymmetric influence of the two types of El Niño and La Niña on summer rainfall over southeast China. J. Climate, 26, 4567-4582, https://doi.org/10.1175/JCLI-D-12-00324.1.

Klein, S. A., B. J. Soden, and N.-C. Lau, 1999: Remote sea surface temperature variations during ENSO: Evidence for a tropical atmospheric bridge. J. Climate, 12, 917-932, https://doi.org/ 10.1175/1520-0442(1999)012<0917:RSSTVD>2.0.CO;2.

Kong, X., J. Mao, and G. Wu, 2017: Influence on the South China rainfall anomalies of the atmospheric quasi-biweekly oscillation in mid-high latitude during the summer of 2002 (in Chinese). Chin. J. Atmos. Sci., 41, 1204-1220, https://doi.org/ 10.3878/j.issn.1006-9895.1703.16277.

Kosaka, Y., S.-P. Xie, N.-C. Lau, and G. A. Vecchi, 2013: Origin of seasonal predictability for summer climate over the northwestern Pacific. Proc. Natl. Acad. Sci. USA, 110, 7574-7579, https://doi.org/10.1073/pnas.1215582110.

Kug, J.-S., F.-F. Jin, and S.-I. An, 2009: Two types of El Niño events: Cold tongue El Niño and warm pool El Niño. J. Climate, 22, 1499-1515, https://doi.org/10.1175/2008JCLI2624.1.

Larkin, N. K., and D. E. Harrison, 2002: ENSO warm (El Niño) and cold (La Niña) event life cycles: Ocean surface anomaly 
patterns, their symmetries, asymmetries, and implications. $J$. Climate, 15, 1118-1140, https://doi.org/10.1175/1520-0442(2002) 015<1118:EWENOA>2.0.CO;2.

Lau, K.-M., and S. Yang, 1997: Climatology and interannual variability of the Southeast Asian monsoon. Adv. Atmos. Sci., 14, 141-162, https://doi.org/10.1007/s00376-997-0016-y.

Lau, N.-C., A. Leetmaa, and M. J. Nath, 2006: Attribution of atmospheric variations in the 1997-2003 period to SST anomalies in the Pacific and Indian Ocean basins. J. Climate, 19 3607-3628, https://doi.org/10.1175/JCLI3813.1.

Lee, M.-H., C.-H. Ho, and J.-H. Kim, 2010: Influence of tropical cyclone landfalls on spatiotemporal variations in typhoon season rainfall over South China. Adv. Atmos. Sci., 27, 443 454, https://doi.org/10.1007/s00376-009-9106-3.

Li, J., and L. Zhang, 2009: Wind onset and withdrawal of Asian summer monsoon and their simulated performance in AMIP models. Climate Dyn., 32, 935-968, https://doi.org/10.1007/ s00382-008-0465-8.

Lin, Z., and B. Wang, 2016: Northern East Asian low and its impact on the interannual variation of East Asian summer rainfall Climate Dyn., 46, 83-97, https://doi.org/10.1007/s00382-0152570-9.

Luo, J.-J, C. Yuan, W. Sasaki, S. Behera, Y. Masumoto, T. Yamgata, J.-Y. Lee, and S. Masson, 2016: Current status of intraseasonalseasonal-to-interannual prediction of the Indo-Pacific climate. Indo-Pacific Climate Variability and Predictability, S. K. Behera and T. Yamagata, Eds., World Scientific, 63-107, https://doi.org/ 10.1142/9789814696623_0003.

Matsuno, T., 1966: Quasi-geostrophic motions in the equatorial area. J. Meteor. Soc. Japan, 44, 25-43, https://doi.org/10.2151/ jmsj1965.44.1_25.

Nitta, T., 1987: Convective activities in the tropical western Pacific and their impact on the Northern Hemisphere summer circulation. J. Meteor. Soc. Japan, 65, 373-390, https://doi.org/ 10.2151/jmsj1965.65.3_373.

Ren, F., B. Gleason, and D. Easterling, 2002: Typhoon impacts on China's precipitation during 1957-1996. Adv. Atmos. Sci., 19, 943-952, https://doi.org/10.1007/s00376-002-0057-1.

Saji, N. H., B. N. Goswami, P. N. Vinayachandran, and T. Yamagata, 1999: A dipole mode in the tropical Indian Ocean. Nature, 401, 360-363, https://doi.org/10.1038/43854.

Seo, K.-H., J. Ok, J.-H. Son, and D.-H. Cha, 2013: Assessing future changes in the East Asian summer monsoon using CMIP5 coupled models. J. Climate, 26, 7662-7675, https://doi.org/10.1175/ JCLI-D-12-00694.1.

Song, F., and T. Zhou, 2014: Interannual variability of East Asian summer monsoon simulated by CMIP3 and CMIP5 AGCMs: Skill dependence on Indian Ocean-western Pacific anticyclone teleconnection. J. Climate, 27, 1679-1697, https://doi.org/10.1175/JCLI-D-13-00248.1.

Srinivas, G., J. S. Chowdary, Y. Kosaka, C. Gnanaseelan, A. Parekh, and K. V. S. R. Prasad, 2018: Influence of the Pacific-Japan pattern on Indian summer monsoon rainfall. J. Climate, 31, 3943-3958, https://doi.org/10.1175/JCLI-D-17-0408.1.

Su, Q., R. Lu, and C. Li, 2014: Large-scale circulation anomalies associated with interannual variation in monthly rainfall over South China from May to August. Adv. Atmos. Sci., 31, 273 282, https://doi.org/10.1007/s00376-013-3051-x.

Tang, W., Z. Sun, and G. Tan, 2008: Effect of Indian Ocean dipole on rainfall anomaly in south of China (in Chinese). J. Nanjing Inst. Meteor., 31, 836-843.

Tao, L., T. Li, Y.-H. Ke, and J.-W. Zhao, 2017: Causes of interannual and interdecadal variations of the summertime Pacific-Japan- like pattern over East Asia. J. Climate, 30, 8845-8864, https:// doi.org/10.1175/JCLI-D-15-0817.1.

Tian, Y., and Q. Wang, 2010: Definition of the South China Sea summer monsoon onset. Chin. J. Oceanol. Limnol., 28, 12811289, https://doi.org/10.1007/s00343-010-9950-0.

Wang, B., Ed., 2006: The Asian Monsoon. Springer-Praxis, 845 pp.

— , and R. Wu, 1997: Peculiar temporal structure of the South China Sea summer monsoon. Adv. Atmos. Sci., 14, 177-194, https://doi.org/10.1007/s00376-997-0018-9.

- — , and X. Fu, 2000: Pacific-East Asian teleconnection: How does ENSO affect East Asian climate? J. Climate, 13, 1517-1536, https://doi.org/10.1175/1520-0442(2000)013<1517: PEATHD $>2.0 . \mathrm{CO} ; 2$.

— LinHo, Y. Zhang, and M.-M. Lu, 2004: Definition of South China Sea monsoon onset and commencement of the East Asia summer monsoon. J. Climate, 17, 699-710, https:// doi.org/10.1175/2932.1.

_ J. Liu, J. Yang, T. Zhou, and Z. Wu, 2009: Distinct principal modes of early and late summer rainfall anomalies in East Asia. J. Climate, 22, 3864-3875, https://doi.org/10.1175/ 2009JCLI2850.1.

_- B. Xiang, and J.-Y. Lee, 2013: Subtropical high predictability establishes a promising way for monsoon and tropical storm predictions. Proc. Natl. Acad. Sci. USA, 110, 2718-2722, https:// doi.org/10.1073/pnas.1214626110.

Weng, H., K. Ashok, S. K. Behera, S. A. Rao, and T. Yamagata, 2007: Impacts of recent El Niño Modoki on dry/wet conditions in the Pacific rim during boreal summer. Climate Dyn., 29, 113-129, https://doi.org/10.1007/s00382-007-0234-0.

- S. K. Behera, and T. Yamagata, 2009: Anomalous winter climate conditions in the Pacific rim during recent El Niño Modoki and El Niño events. Climate Dyn., 32, 663-674, https:// doi.org/10.1007/s00382-008-0394-6.

Wu, B., T. Zhou, and T. Li, 2017a: Atmospheric dynamic and thermodynamic processes driving the western North Pacific anomalous anticyclone during El Niño. Part I: Maintenance mechanisms. J. Climate, 30, 9621-9635, https://doi.org/10.1175/ JCLI-D-16-0489.1.

- — , and - 2017b: Atmospheric dynamic and thermodynamic processes driving the western North Pacific anomalous anticyclone during El Niño. Part II: Formation processes. J. Climate, 30, 9637-9650, https://doi.org/10.1175/JCLI-D-160495.1.

Wu, G., Y. Liu, B. He, Q. Bao, A. Duan, and F.-F. Jin, 2012: Thermal controls on the Asian summer monsoon. Sci. Rep., 2, 404, https://doi.org/10.1038/srep00404.

Wu, R. G., G. Huang, Z. C. Du, and K. M. Hu, 2014: Cross-season relation of the South China Sea precipitation variability between winter and summer. Climate Dyn., 43, 193-207, https://doi.org/10.1007/s00382-013-1820-y.

Wu, T.-W., and Z.-A. Qian, 2003: The relation between the Tibetan winter snow and the Asian summer monsoon and rainfall: An observational investigation. J. Climate, 16, 2038-2051, https:// doi.org/10.1175/1520-0442(2003)016<2038:TRBTTW >2.0.CO;2.

Xie, S.-P., K. Hu, J. Hafner, H. Tokinaga, Y. Du, G. Huang, and T. Sampe, 2009: Indian Ocean capacitor effect on Indo-western Pacific climate during the summer following El Niño. J. Climate, 22, 730-747, https://doi.org/10.1175/ 2008JCLI2544.1.

- Y. Kosaka, Y. Du, K. Hu, J. S. Chowdary, and G. Huang, 2016: Indo-western Pacific Ocean capacitor and coherent climate anomalies in post-ENSO summer: A review. Adv. Atmos. Sci., 33, 411-432, https://doi.org/10.1007/s00376-015-5192-6. 
Xu, L., 1994: Heavy losses in South China and large arid area in North and Northeast China (in Chinese). Meteor. Mon., 9, 62-63.

Yang, H., and S. Sun, 2005: The characteristics of longitudinal movement of the subtropical high in the western Pacific in the pre-rainy season in South China. Adv. Atmos. Sci., 22, 392400, https://doi.org/10.1007/BF02918752.

Yang, J., Q. Liu, Z. Liu, L. Wu, and F. Huang, 2009: Basin mode of Indian Ocean sea surface temperature and Northern Hemisphere circumglobal teleconnection. Geophys. Res. Lett., 36, L19705, https://doi.org/10.1029/2009GL039559.

Yang, K., T. Hu, and C. Wang, 2017: A numerical study on the relationship between the spring-winter snow cover anomalies over the northern and southern Tibetan Plateau and summer precipitation in East China (in Chinese). Chin. J. Atmos. Sci., 41, 345-356.

You, Q., and Coauthors, 2011: Changes in daily climate extremes in China and their connection to the large scale atmospheric circulation during 1961-2003. Climate Dyn., 36, 2399-2417, https://doi.org/10.1007/s00382-009-0735-0.

Yu, J.-Y., and H.-Y. Kao, 2007: Decadal changes of ENSO persistence barrier in SST and ocean heat content indices: 19582001. J. Geophys. Res., 112, D13106, https://doi.org/10.1029/ 2006JD007654.

Yuan, F., and W. Chen, 2013: Roles of the tropical convective activities over different regions in the earlier onset of the South China Sea summer monsoon after 1993. Theor. Appl. Climatol., 113, 175-185, https://doi.org/10.1007/s00704-012-0776-x.

- K. Wei, W. Chen, S. K. Fong, and K. C. Leong, 2010: Temporal variations of the frontal and monsoon storm rainfall during the first rainy season in South China. Atmos. Oceanic Sci. Lett., 3, 243-247, https://doi.org/10.1080/16742834.2010.11446876.
Zhai, P., X. Zhang, H. Wan, and X. Pan, 2005: Trends in total precipitation and frequency of daily precipitation extremes over China. J. Climate, 18, 1096-1108, https://doi.org/10.1175/ JCLI-3318.1.

Zhang, Q., X. Gu, J. Li, P. Shi, and V. P. Singh, 2018: The impact of tropical cyclones on extreme precipitation over coastal and inland areas of China and its association to the ENSO. J. Climate, 31, 1865-1880, https://doi.org/10.1175/JCLI-D-170474.1.

Zhang, X., L. Alexander, G. C. Hegerl, P. Jones, A. Klein Tank, T. C. Peterson, B. Trewin, and F. W. Zwiers, 2011: Indices for monitoring changes in extremes based on daily temperature and precipitation data. Wiley Interdiscip. Rev.: Climate Change, 2 , 851-870, https://doi.org/10.1002/wcc.147.

Zhang, Y., T. Li, and B. Wang, 2004: Decadal changes of the spring snow depth over the Tibetan Plateau: The associated circulation and influence on the East Asian summer monsoon. J. Climate, 17, 2780-2793, https://doi.org/10.1175/ 1520-0442(2004)017<2780:DCOTSS > 2.0.CO;2.

Zhao, P., X. Zhang, X. Zhou, M. Ikeda, and Y. Yin, 2004: The sea ice extent anomaly in the North Pacific and its impact on the East Asian summer monsoon rainfall. J. Climate, 17, 3434-3447, https:// doi.org/10.1175/1520-0442(2004)017<3434:TSIEAI >2.0.CO;2.

Zhou, B., Q. H. Wen, Y. Xu, L. Song, and X. Zhang, 2014: Projected changes in temperature and precipitation extremes in China by the CMIP5 multimodel ensembles. J. Climate, 27, 6591-6611, https://doi.org/10.1175/JCLI-D-13-00761.1.

Zhu, C. W., W.-S. Lee, H. Kang, and C.-K. Park, 2005: A proper monsoon index for seasonal and interannual variations of the East Asian monsoon. Geophys. Res. Lett., 32, L02811, https:// doi.org/10.1029/2004GL021295. 